\title{
Diagnosis and predictive clinical and para-clinical cutoffs for diabetes complications in Lur and Lak populations of Iran; a ROC curve analysis to design a regional guideline
}

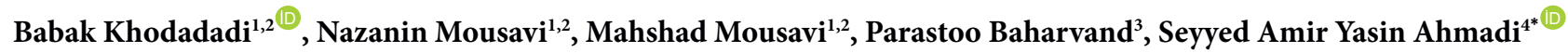 \\ ${ }^{1}$ Exceptional Talent Development Center, Education Development Center, Lorestan University of Medical Sciences, Khorramabad, Iran \\ ${ }^{2}$ Scientific Society of Evidence-Based Knowledge, Research office for the History of Persian Medicine, Lorestan University of Medical Sciences, \\ Khorramabad, Iran \\ ${ }^{3}$ Social Determinants of Health Research Center, Lorestan University of Medical Sciences, Khorramabad, Iran \\ ${ }^{4}$ Pediatric Growth and Development Research Center, Institute of Endocrinology and Metabolism, Iran University of Medical Sciences, Tehran, Iran
}

\section{A R T I C L E I N F O}

Article Type:

ORIGINAL

\section{Article History:}

Received: 11 February 2018

Accepted: 25 July 2018

ePublished: 17 August 2018

\section{Keywords:}

Diabetes complications

Diabetic nephropathy

Diabetes mellitus

Microvascular complications

Cardiovascular disease

Peripheral vessel disease

\begin{abstract}
A B S T R A C T
Introduction: American Diabetes Association updates its guideline every year. However this guideline can be changed for different populations based on their cultural and genetic status. Objectives: We intend to design a regional study in Lur and Lak populations of Iran using receiver operating characteristics (ROC) curve model.

Patients and Methods: A total of 133 diabetes mellitus (DM) patients were enrolled in this study. The collected information for each patient were gender, age, body mass index (BMI), DM type, DM duration, fasting blood sugar (FBS), hemoglobin Alc (HbAlc), lipid profile, type of treatments, type of statin and dose, documented neuropathy, documented nephropathy, symptomatic retinopathy, peripheral vessel disease (PVD), documented cardiovascular disease (CVD), food ulcer history, dawn effect, systolic blood pressure (SBP), and diastolic blood pressure (DBP). ROC curve was used and area under curve (AUC) was reported.

Results: For neuropathy, age was the most accurate diagnostic index (area under curve [AUC] $=79 \%$ ). For nephropathy SBP was the most accurate diagnostic index (AUC $=88 \%)$. For symptomatic retinopathy DM duration was the most accurate diagnostic index (AUC $=81 \%$ ). For PVD, HDL-C was the most accurate diagnostic index (reverse AUC $=67 \%$ ). For CVD age was the most accurate diagnostic index $(\mathrm{AUC}=81 \%)$. For foot ulcer history age was the most accurate diagnostic index (AUC= $85 \%)$.

Conclusion: The final suggested guideline is like the international guidelines. However some unique points should be regarded. Blood pressure $>165 / 110 \mathrm{~mm} \mathrm{Hg}$ is diagnostic of diabetic nephropathy. Additionally serum high-density lipoprotein (HDL-C) $>48 \mathrm{mg} / \mathrm{dL}$ is strongly suggested.
\end{abstract}

Implication for health policy/practice/research/medical education:

Diabetes management guidelines can be changed for different populations based on their cultural and genetic status. In this region, blood pressure $>165 / 110 \mathrm{~mm} \mathrm{Hg}$ is diagnostic of diabetic nephropathy. Additionally serum HDL-C $>48 \mathrm{mg} / \mathrm{dl}$ is strongly suggested for the prevention of diabetes complications.

Please cite this paper as: Khodadadi B, Mousavi N, Mousavi M, Baharvand P, Ahmadi SAY. Diagnosis and predictive clinical and para-clinical cutoffs for diabetes complications in Lur and Lak populations of Iran; a ROC curve analysis to design a regional guideline. J Nephropharmacol. 2018;7(2):83-89.

\section{Introduction}

Diabetes mellitus (DM) as a global health issue, is a complex multifactorial chronic disease and a growing epidemic illness with chronic macro- and microvascular complications (1-4) as well as psychological problems (5). DM and its complications account for 5\% of all deaths worldwide annually (6,7). Hyperlipidemia and dyslipidemia increase the risk of microvascular complications including retinopathy, nephropathy and neuropathy as well as macrovascular complications such as cardiovascular disease (CVD). CVD is the major cause of mortality and morbidity in type 2 DM (T2DM) 
patients, which is responsible for near to $50 \%$ of all deaths globally $(1,3,8-10)$. In patients of type $2 \mathrm{DM}$, the risk of CVD is 2 to 4 times of people without DM $(3,11)$. Insulin resistant increases free fatty acid levels and lipoproteins in the blood which potentiate the risk factor of dyslipidemia and atherosclerosis (12-15). Dyslipidemia is responsible for $1 / 2$ cases of ischemic heart disease and $1 / 5$ cases of strokes $(8,16)$. Hence, early diagnosis of dyslipidemia in high-risk patients with DM is necessary for reducing the risk of acute and chronic complications $(6,8)$. Hemoglobin A1c (HbA1c) predicts both macro and microvascular complications of DM which indicates the mean glycemic values in the recent three months $(17,18)$. The positive correlation between HbAlc with total cholesterol (TC), triglyceride (TG), low-density lipoprotein (LDL-C) and very low-density lipoprotein (VLDL) levels were detected. Additionally, the negative correlation of $\mathrm{HbA1c}$ with highdensity lipoprotein (HDL-C) levels has shown in both male and females $(6-8,19)$. Hemoglobin A1c can be used to predict dyslipidemia and glycemic values and diabetics complications $(6,8)$.

\section{Objectives}

American diabetes association updates its guideline every year. This guideline is obtained based on evidencebased medicine. Various parts of this guideline are based on systematic reviews and meta-analyses. They include various populations an ethnicities. However, this guideline can be changed for different populaces based on their cultural and genetic status. Therefore, we intend to design a regional study in Khorramabad, Lorestan province, west of Iran, emphasizing on blood pressure and lipid profile cutoffs.

\section{Patients and Methods \\ Design}

This analytic cross-sectional study was conducted based on Standards for Reporting of Diagnostic Accuracy Studies (STARD) guidelines (available from http://www. equator-network.org/reporting-guidelines/stard/). This study has been done in the Khorramabad hospitals having endocrinology/internal medicine ward or clinics (Shahid Rahimi, and Sohadaye Ashayer). The sampling method was census in the second half of 2017.

\section{Participants}

Totally 150 known cases of type 1 and type 2 diabetes were found. However according to some incomplete information, only 133 patients were enrolled in this study. The ethnicities of the patients were Lur and Lak as their gene pools of human leukocyte antigen (HLA) have been previously reported $(20,21)$. History taking and physical examination were done. The collected information for each patient were gender, age, body mass index (BMI), DM type, DM duration, fasting blood sugar (FBS), HbA1c, LDL-C, HDL-C, TG, type of DM treatment, type of statin and dose, documented neuropathy, documented nephropathy, symptomatic retinopathy, peripheral vessel disease (PVD), documented CVD, food ulcer history, dawn effect, systolic blood pressure (SBP), and diastolic blood pressure (DBP). In addition, the cumulative daily equivalent dose of atorvastatin, and estimated level of LDL-C without statin therapy were calculated in Excel 2013 (Microsoft, USA).

\section{Test methods}

The gold standard definition of each term is based on the following points; neuropathy (documented cases based on history and physical examination); nephropathy (documented cases based on micro-albuminuria); retinopathy (merely symptomatic cases with the history of laser or surgical therapy or being candidates of such procedures); PVD (documented cases based on history and physical examination); CVD (documented cases based on cardiology consultant); dawn effect (nausea during night sleep and morning hyperglycemia merely based on portable glucometer); cumulative atorvastatin equivalent [calculated based on (22)]; real LDL-C (estimation of LDL-C if there is not administration of statin based on the lower limit of LDL-C reduction in each statin dose) (22).

\section{Ethical issues}

The research followed the tenets of the Declaration of Helsinki. This study has been registered in the ethics committee of Lorestan University of Medical Sciences with registration number IR.LUMS.REC.1393.19. The informed consent was obtained. The raw data are originally obtained and available online (https://data. mendeley.com/datasets/k62fdsnwkg/1).

\section{Statistical analysis}

Based on central tendency and enough sample size of each possible group ( $>30)$, we considered normal distribution for numerical data. Independent $t$ test with equal variance was used. Receiver operating characteristics (ROC) curve was used for $P<0.05$. Thereafter if area under curve (AUC) was $>65 \%$ the cutoffs of that parameter would be reported. Three cutoffs would be reported; 1) one of the optimal cutoffs in the northwest of the ROC curve; 2 ) the most median cutoff with sensitivity $100 \%$; 3) the most median cutoff with specificity $100 \%$. Sensitivity $100 \%$ was considered as negative predictive value (NPV) 100\%, and specificity $100 \%$ considered as positive predictive value (PPV) 100\%. STATA14 software (StataCorp LLC, US) was used.

\section{Results \\ T test results}

Two-tailed $P$ values are reported in Table 1 . The relations (significant at $P<0.05$ ) are considered for ROC curve analysis. For $t$ test-based judgement we used Bonferroni's correction because of 70 simultaneous analysis. Then $P<0.0007$ was considered as a corrected significance level. After correction, age and DM duration was the 
Table 1. T test analysis results

\begin{tabular}{|c|c|c|c|c|c|c|c|c|c|c|}
\hline Complication & $\begin{array}{l}\text { Age } \\
\text { (y) }\end{array}$ & $\begin{array}{c}\text { BMI } \\
\mathrm{kg} / \mathrm{m}^{2} \text { ) }\end{array}$ & $\begin{array}{l}\text { DM duration } \\
\text { (y) }\end{array}$ & $\begin{array}{c}\text { FBS } \\
(\mathrm{mg} / \mathrm{dL})\end{array}$ & $\begin{array}{c}\text { HbA1c } \\
(\%)\end{array}$ & $\begin{array}{c}\text { LDL-C } \\
\text { (mg/dL) }\end{array}$ & $\begin{array}{c}\text { HDL-C } \\
\text { (mg/dL) }\end{array}$ & $\begin{array}{c}\text { TG } \\
(\mathrm{mg} / \mathrm{dL})\end{array}$ & $\begin{array}{c}\text { SBP } \\
(\mathrm{mm} \mathrm{Hg})\end{array}$ & $\begin{array}{c}\text { DBP } \\
(\mathrm{mm} \mathrm{Hg})\end{array}$ \\
\hline Neuropathy & $<0.0001^{b}$ & 0.1648 & $<0.0001^{b}$ & $0.0042^{\mathrm{a}}$ & 0.1585 & 0.3365 & $<0.0001^{b}$ & $0.0185^{a}$ & $0.0153^{a}$ & $0.0073^{a}$ \\
\hline Nephropathy & $<0.0001^{\mathrm{b}}$ & $0.0000^{b}$ & $<0.0001^{b}$ & $0.0001^{b}$ & 0.0555 & $<0.0001^{\mathrm{b}}$ & $0.0148^{a}$ & $0.0001^{b}$ & $<0.0001^{b}$ & $<0.0001^{\text {b }}$ \\
\hline Retinopathy & $<0.0001^{\mathrm{b}}$ & 0.1276 & $<0.0001^{\mathrm{b}}$ & $0.0006^{b}$ & $0.0306^{a}$ & $0.0140^{\mathrm{a}}$ & $0.0037^{a}$ & $0.0125^{a}$ & $<0.0001^{\mathrm{b}}$ & $<0.0001^{b}$ \\
\hline PVD & $<0.0001^{b}$ & 0.3410 & $<0.0001^{\mathrm{b}}$ & $0.0195^{a}$ & 0.0528 & 0.4782 & $0.0004^{b}$ & $0.0129^{a}$ & 0.2161 & 0.1026 \\
\hline CVD & $<0.0001^{\mathrm{b}}$ & 0.0635 & $<0.0001^{b}$ & $0.0003^{b}$ & $0.0409^{a}$ & 0.1659 & $<0.0001^{b}$ & $<0.0001^{b}$ & $0.0002^{\mathrm{b}}$ & $<0.0001^{b}$ \\
\hline Foot ulcer & $<0.0001^{b}$ & $0.0012^{\mathrm{a}}$ & $<0.0001^{b}$ & 0.2259 & $0.0289^{a}$ & 0.1576 & $0.0001^{b}$ & $0.0142^{\mathrm{a}}$ & $0.0003^{b}$ & $0.0002^{b}$ \\
\hline Dawn effect & 0.7799 & 0.1493 & 0.2494 & 0.3914 & 0.3962 & $0.0001^{b c}$ & 0.2109 & 0.7339 & $0.0231^{\mathrm{ac}}$ & 0.2408 \\
\hline
\end{tabular}

Abbreviations: PVD, peripheral vessel disease; CVD, cardiovascular disease.

Each numerical parameter is evaluated in each nominal complication.

a Significant at $P<0.05$; ${ }^{\text {b }}$ Significant at $P<0.0007$; ${ }^{c}$ LDL-C and SBP had protecting effect for dawn effect.

most associated parameters with diabetes complications. FBS was associated with nephropathy, symptomatic retinopathy and CVD. Blood pressure was associated with nephropathy, symptomatic retinopathy and CVD and also foot ulcer history. Among the lipid profile, HDL-C was associated with neuropathy, PVD, CVD and foot ulcer history. TG was associated with nephropathy and CVD. LDL-C was only associated with nephropathy. HbA1C was not an independent associated factor. LDL-C was a protecting factor for dawn effect.

\section{Linear regression results}

The $P$ values and effect directions are shown in Table 2 . For regression-based judgement we applied Bonferroni's correction because of 45 simultaneous analysis. Then $P<0.001$ was considered as a corrected significance level. After applying the correction, age versus DM duration and SBP versus DBP had positive correlations. A negative correlation was found for HDL-C versus TG (Table 2). Real LDL-C was associated with age, LDL-C and cumulative atorvastatin equivalent. In contrast to LDL-C versus age, the positive correlation of real LDL-C with age was statistically significant (Figure 1).

\section{ROC curve results}

The cutoffs obtained from ROC curve analysis are shown in Table 3. The graphs of these ROC curves are shown in Figure 2A-F. The ROC curve of dawn effect is not shown due to its inconclusive results. For neuropathy, age was the most accurate diagnostic index (area under curve $[$ AUC $]=79 \%)$. For nephropathy SBP was the most accurate diagnostic index $(\mathrm{AUC}=88 \%)$. For symptomatic retinopathy $\mathrm{DM}$ duration was the most accurate diagnostic index $(\mathrm{AUC}=81 \%)$. For PVD, HDL-C was the most accurate diagnostic index (reverse AUC $=100-33 \%$ ). For CVD age was the most accurate diagnostic index (AUC= $81 \%)$. For foot ulcer history, age was the most accurate diagnostic index $(\mathrm{AUC}=85 \%)$.

\section{Discussion}

This study was aimed to reach a regional guideline. Generally our results were similar to international guidelines; however there were some unique results. Mainly our dissimilarities were related to HbAlc. This can be justified through this fact that results of HbA1c evaluation are methodological and technical dependent $(23,24)$. Moreover, based on the World

Table 2. Linear regression matrix ( $P$ value and effect direction)

\begin{tabular}{|c|c|c|c|c|c|c|c|c|c|c|}
\hline $\begin{array}{l}\text { Numerical } \\
\text { parameter }\end{array}$ & $\begin{array}{l}\text { Age } \\
\text { (y) }\end{array}$ & $\begin{array}{c}\text { BMI } \\
\left(\mathrm{kg} / \mathrm{m}^{2}\right)\end{array}$ & $\begin{array}{c}\text { DM duration } \\
\text { (y) }\end{array}$ & $\begin{array}{c}\text { FBS } \\
(\mathrm{mg} / \mathrm{dL})\end{array}$ & $\begin{array}{c}\text { HbA1c } \\
(\%)\end{array}$ & $\begin{array}{c}\text { LDL-C } \\
\text { (mg/dL) }\end{array}$ & $\begin{array}{l}\text { HDL-C } \\
\text { (mg/dL) }\end{array}$ & $\begin{array}{c}\text { TG } \\
(\mathrm{mg} / \mathrm{dL})\end{array}$ & $\begin{array}{c}\text { SBP } \\
(\mathrm{mm} \mathrm{Hg})\end{array}$ & $\begin{array}{c}\text { DBP } \\
(\mathrm{mm} \mathrm{Hg})\end{array}$ \\
\hline Age & NA & & & & & & & & & \\
\hline BMI & $0.040^{\mathrm{a}}+$ & NA & & & & & & & & \\
\hline DM duration & $0.000^{b}+$ & 0.464 & NA & & & & & & & \\
\hline FBS & 0.930 & $0.029^{a}-$ & 0.238 & NA & & & & & & \\
\hline $\mathrm{HbA1c}$ & 0.223 & 0.221 & 0.484 & 0.131 & NA & & & & & \\
\hline LDL-C & 0.744 & 0.623 & 0.393 & 0.106 & 0.845 & NA & & & & \\
\hline HDL-C & 0.250 & 0.203 & 0.528 & 0.582 & 0.554 & $0.007^{a}+$ & NA & & & \\
\hline TG & 0.077 & 0.731 & 0.121 & 0.069 & 0.610 & $0.044^{a}+$ & $0.000^{b}-$ & NA & & \\
\hline SBP & 0.090 & $0.007^{a}+$ & $0.009^{a}+$ & 0.084 & 0.430 & $0.008^{a}+$ & 0.589 & 0.499 & NA & \\
\hline DBP & 0.195 & 0.516 & 0.371 & 0.458 & 0.103 & 0.088 & 0.463 & 0.343 & $0.000^{\mathrm{b}}+$ & NA \\
\hline
\end{tabular}

Abbreviations: BMI, body mass index; DM, diabetes mellitus; FBS, fasting blood sugar; HbA1c, hemoglobin A1c; TG, triglyceride; LDL-C, low-density lipoprotein; HDL-C, high-density lipoprotein; SBP, systolic blood pressure; DBP, diastolic blood pressure.

All numerical parameters are compared two by two for correlation.

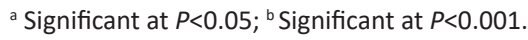




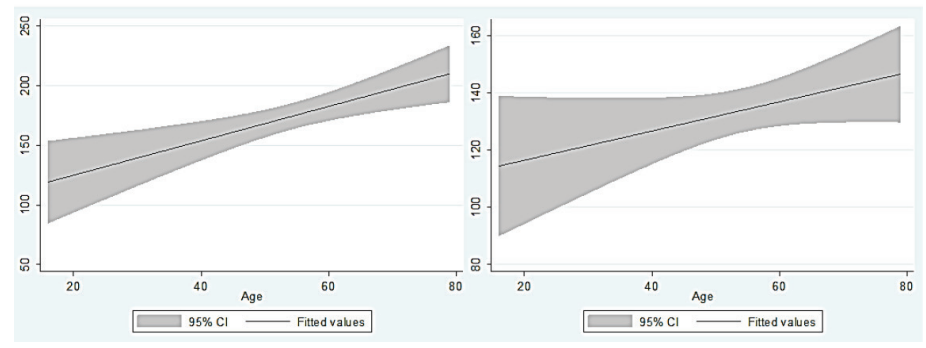

Figure 1. Regression of real LDL-C VS age (left) and LDL-C VS age (right). The left one is statistically significant $(P<0.05)$.

Health Organization report, HbAlc needs an accurate evaluation (25). In contrast to our study, a study in Egypt showed significant results for HbAlc (26). Regarding our t test analysis results, age and DM duration were the most associated parameter with diabetes complications as expected. Among the lipid profile, HDL-C was more important than TG. Additionally, TG was more important than LDL-C. This finding confirms this fact that LDL-C is not included as a metabolic syndrome criterion (27). Regarding dawn effect, while LDL-C was a protecting factor, it should not be regarded as a protecting factor because of its harmful effects. Regarding our regression analysis, the only notable finding was the negative correlation of HDL-C with TG. Positive correlation of
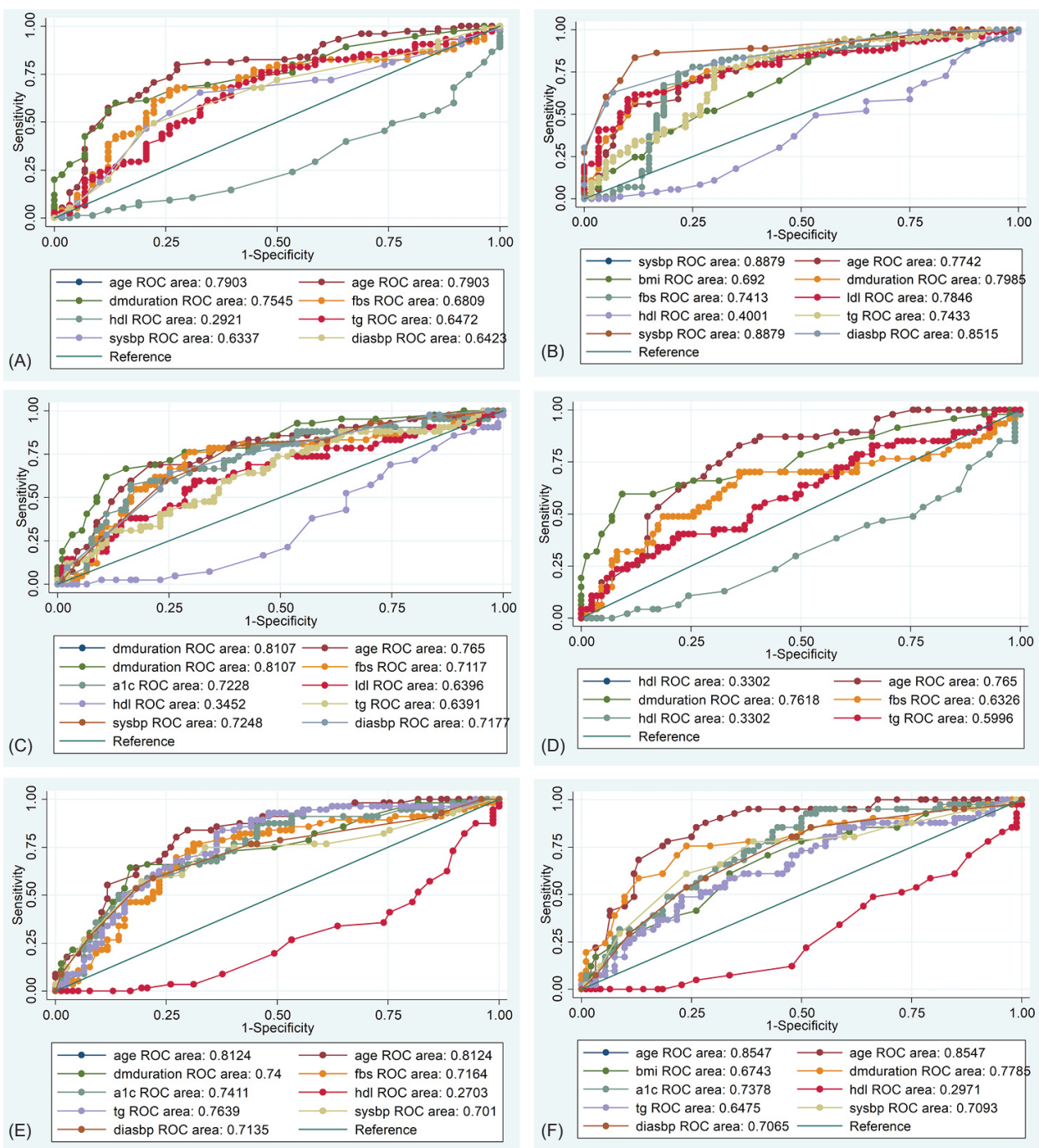

Figure 2. ROC curves for (A) diagnostic accuracy of neuropathy, (B) diagnostic accuracy of nephropathy, (C) diagnostic accuracy of symptomatic retinopathy, (D) diagnostic accuracy of PVD, (E) diagnostic accuracy of CVD and (F) diagnostic accuracy of foot ulcer history. 
real LDL-C with age (not shown in Table 2) in spite of lack of this correlation in LDL-C with age, shows that administration of statin can prevent LDL-C increasing due to cumulative effect of age. Regarding our ROC curve analysis, only SBP for nephropathy and HDL-C for PVD took over cumulative effect of age and DM duration. Among the predictive cutoffs (Table 3), FBS and HbA1c had a negative predictive value of around $100 \%$ cutoffs, However, they should not be considered for prevention of diabetes complications because of hypoglycemia danger. Additionally, blood pressure negative predictive value of around $100 \%$ cutoffs should not be considered for the prevention of diabetes complications because of renal hypoperfusion and syncope danger. However, HDL-C at $44 \mathrm{mg} / \mathrm{dL}, 46 \mathrm{mg} / \mathrm{dL}, 48 \mathrm{mg} / \mathrm{dL}$ and $48 \mathrm{mg} / \mathrm{dL}$ can be considered for prevention of foot ulcer, CVD, PVD and symptomatic retinopathy, respectively. FBS cutoffs seem not to be reliable because of their wide distribution values and susceptibility to insulin regimen. Among the positive predictive value of about $100 \%$ cutoffs, age of 79 years and DM duration 20-28of years should be considered for prediction of all diabetes complications. SBP $>165 \mathrm{~mm}$ $\mathrm{Hg}$ should be considered for diagnosis of nephropathy. SBP $>180 \mathrm{~mm} \mathrm{Hg}$ should be considered for diagnosis of symptomatic retinopathy, CVD and prediction of foot ulcer. DBP $>110 \mathrm{~mm} \mathrm{Hg}$ should be considered for

Table 3. Cutoffs obtained from ROC curve analysis

\begin{tabular}{|c|c|c|c|c|}
\hline & Parameter & ROC curve cutoff & PPV $100 \%$ cutoff & NPV $100 \%$ cutoff \\
\hline \multirow{4}{*}{ Neuropathy } & Age (y) & $53(80 \% / 72 \%)^{*}$ & 79 & 33 \\
\hline & DM duration $(\mathrm{y})$ & 12 (60\%/86\%) & 20 & $<1$ \\
\hline & $\mathrm{FBS}(\mathrm{mg} / \mathrm{dL})$ & 200 (68\%/72\%) & 510 & 80 \\
\hline & HDL-C (mg/dL) & 40 (76\%/53\%) & 28 & 60 \\
\hline \multirow{7}{*}{ Nephropathy } & Sys BP (mm Hg) & 150 (83\%/88\%) & 165 & 110 \\
\hline & Dias BP (mm Hg) & 95 (63\%/93\%) & 110 & 70 \\
\hline & DM duration $(y)$ & 9 (75\%/71\%) & 26 & 2 \\
\hline & LDL-C (mg/dL) & 128 (79\%/63\%) & 188 & 36 \\
\hline & Age (y) & 54 (75\%/68\%) & 79 & 36 \\
\hline & $\mathrm{FBS}(\mathrm{mg} / \mathrm{dL})$ & 198 (78\%/75\%) & 510 & 100 \\
\hline & BMI $\left(\mathrm{kg} / \mathrm{m}^{2}\right)$ & 25 (95\%/33\%) & 41 & 19 \\
\hline \multirow{7}{*}{ Retinopathy } & DM duration $(y)$ & 15 (61\%/89\%) & 26 & 2 \\
\hline & Age (y) & 61 (69\%/79\%) & 79 & 31 \\
\hline & Sys BP (mm Hg) & 160 (59\%/75\%) & 180 & 110 \\
\hline & $\mathrm{A} 1 \mathrm{C}(\%)$ & 10.9 (57\%/83\%) & 13.3 & 6.8 \\
\hline & Dias BP (mm Hg) & 95 (64\%/74\%) & 120 & 70 \\
\hline & $\mathrm{FBS}(\mathrm{mg} / \mathrm{dL})$ & 250 (54\%/82\%) & 510 & 110 \\
\hline & $\mathrm{HDL}-\mathrm{C}(\mathrm{mg} / \mathrm{dL})$ & 39 (78\%/51\%) & 21 & 48 \\
\hline \multirow{3}{*}{ Peripheral vessel disease } & Age (y) & $60(63 \% / 76 \%)$ & 79 & 43 \\
\hline & DM duration (y) & 15 (59\%/90\%) & 21 & $<1$ \\
\hline & $\mathrm{HDL}-\mathrm{C}(\mathrm{mg} / \mathrm{dL})$ & 35 (51\%/75\%) & 21 & 48 \\
\hline \multirow{8}{*}{ Cardiovascular disease } & Age (y) & $55(83 \% / 70 \%)$ & 76 & 39 \\
\hline & TG $(\mathrm{mg} / \mathrm{dL})$ & $181(83 \% / 62 \%)$ & 565 & 96 \\
\hline & $\mathrm{A} 1 \mathrm{C}(\%)$ & $10.1(58 \% / 79 \%)$ & 13.3 & 7.1 \\
\hline & DM duration $(y)$ & 13 (64\%/83\%) & 29 & $<1$ \\
\hline & $\mathrm{FBS}(\mathrm{mg} / \mathrm{dL})$ & 200 (76\%/68\%) & 510 & 80 \\
\hline & Dias BP (mm Hg) & 95 (58\%/77\%) & 120 & 70 \\
\hline & Sys BP (mm Hg) & $160(57 \% / 80 \%)$ & 180 & 110 \\
\hline & $\mathrm{HDL}-\mathrm{C}(\mathrm{mg} / \mathrm{dL})$ & 35 (80\%/53\%) & 22 & 46 \\
\hline \multirow{7}{*}{ Foot ulcer history } & Age (y) & $63(68 \% / 86 \%)$ & 79 & 45 \\
\hline & DM duration $(y)$ & $15(58 \% / 86 \%)$ & 28 & $<1$ \\
\hline & $\mathrm{A} 1 \mathrm{C}(\%)$ & 12.2 (31\%/91\%) & 13.3 & 6.6 \\
\hline & Sys BP (mm Hg) & 165 (29\%/91\%) & 180 & 110 \\
\hline & Dias BP (mm Hg) & $110(29 \% / 89 \%)$ & 120 & 60 \\
\hline & $\mathrm{BMI}\left(\mathrm{kg} / \mathrm{m}^{2}\right)$ & $36(17 \% / 96 \%)$ & 41 & 19 \\
\hline & $\mathrm{HDL}-\mathrm{C}(\mathrm{mg} / \mathrm{dL})$ & $35(48 \% / 72 \%)$ & 21 & 44 \\
\hline
\end{tabular}

Three cutoffs are reported; a selected cutoff with high accuracy, cutoff with the highest PPV, and cutoff with the highest NPV.

* (sensitivity/specificity) 
diagnosis of nephropathy. DBP >120 mm Hg should be considered for diagnosis of symptomatic retinopathy, CVD and prediction of foot ulcer and finally LDL-C $>188$ $\mathrm{mg} / \mathrm{dL}$ can be considered for diagnosis of nephropathy. It should be regarded that these cutoffs are merely reliable for diabetic patients.

\section{Conclusion}

The final suggested guideline is like the international guidelines. However some unique points should be regarded. HbA1c evaluation in this region should be used only for evaluation of diabetes control and is not suitable as diagnostic or predictive marker of diabetes complications. Diabetic patients at the age of 79 years or with DM duration of more than 20-28 years have a potential to have all diabetes complications. Blood pressure $>165 / 110 \mathrm{~mm}$ $\mathrm{Hg}$ is diagnostic of diabetic nephropathy. HDL-C $>48$ $\mathrm{mg} / \mathrm{dL}$ is strongly suggested. A cohort study should be performed in our region in order to reevaluate predictive values.

\section{Study limitations}

The limitations of our study are lack of evaluation of other diabetes complications and lack of subgroup analysis (e.g. for diabetes type). It is suggested that such missing analysis to be performed in future based our freely available data supplements.

\section{Conflicts of interest}

We declare that there is no commercial conflict of interest for the manufactures of laboratory products such as A1c kits, and there is no cultural or political conflict of interest for the mentioned ethnicities. This study will be used to program a registry system in this region by Babak Khodadadi, Nazanin Mousavi and Mahshad Mousavi, members of talented students committee, educational development center (EDC), Lorestan University of Medical Sciences.

\section{Authors' contribution}

BK and NM are equal first authors. BK designed the idea. $\mathrm{BK}, \mathrm{NM}$ and $\mathrm{MM}$ conducted clinical practice. $\mathrm{PB}$ was epidemiological supervisor. SAYA prepared the primary draft and finalized the manuscript.

\section{Ethical considerations}

Ethical issues (including plagiarism, data fabrication, double publication) have been completely observed by the authors.

\section{Funding/Support}

None.

\section{References}

1. ADA. Standards of Medical Care in Diabetes. American Diabetes Association; 2018.

2. Hu FB. Globalization of diabetes: the role of diet, lifestyle, and genes. Diabetes Care. 2011;34:1249-57. doi: 10.2337/ dc11-0442

3. Huri HZ, Ling DY, Ahmad WA. Association between glycemic control and antidiabetic drugs in type 2 diabetes mellitus patients with cardiovascular complications. Drug Des Devel Ther. 2015;9:4735-49. doi: 10.2147/dddt.s87294

4. Hosseini SM, Amini M, Roosta S, Beigrezaei S. Trends of serum creatinine among patients with type 2 diabetes in Isfahan endocrine and metabolism research center; a longitudinal study. J Prev Epidemiol. 2017;2:e01.

5. Azami M, Moslemirad M, Mansouri A, Khataee M, Sayehmiri K. The prevalence of depression in patients with diabetes in Iran. J Babol Univ Med Sci. 2017;19:16-27.

6. Hussain A, Ali I, Ijaz M, Rahim A. Correlation between hemoglobin A1c and serum lipid profile in Afghani patients with type 2 diabetes: hemoglobin Alc prognosticates dyslipidemia. Ther Adv Endocrinol Metab. 2017;8:51-7. doi: 10.1177/2042018817692296

7. VinodMahato R, Gyawali P, Raut PP, Regmi P, Singh KP, Pandeya DR, et al. Association between glycaemic control and serum lipid profile in type 2 diabetic patients: Glycated haemoglobin as a dual biomarker. Biomed Res. 2011;22:375-80.

8. Bal BS, Salwan SK, Chandarana U. Study of Association between $\mathrm{HbAlc}$ level and lipid profile in type 2 diabetes mellitus. Ann Int Med Dent Res. 2017;3:36-9. doi: 10.21276/ aimdr.2017.3.2.ME9

9. Stratton IM, Adler AI, Neil HAW, Matthews DR, Manley SE, Cull CA, et al. Association of glycaemia with macrovascular and microvascular complications of type 2 diabetes (UKPDS 35): prospective observational study. BMJ. 2000;321:405-12. doi: 10.1136/bmj.321.7258.405

10. Turner R, Millns H, Neil H, Stratton I, Manley S, Matthews D, et al. Risk factors for coronary artery disease in non-insulin dependent diabetes mellitus: United Kingdom Prospective Diabetes Study (UKPDS: 23). BMJ. 1998;316:823-8. doi: 10.1136/bmj.316.7134.823

11. WHO. Cardiovascular Disease Risk Factors: Diabetes. Geneva, Switzerland: World Heart Organization; 2014.

12. Durrington P. Dyslipidaemia. Lancet. 2003;362:717-31. doi: 10.1016/s0140-6736(03)14234-1

13. Krauss RM. Dietary and genetic probes of atherogenic dyslipidemia. Arterioscler Thromb Vasc Biol. 2005;25:226572. doi: 10.1161/01.ATV.0000186365.73973.f0

14. Mehravar F, Mansournia MA, Abolhassani M, HolakouieNaieni K, Nasli-Esfahani E. The association between serum lipids profile and $\mathrm{HbAlc}$ in type 2 diabetes mellitus in Tehran, Iran. Int J Epidemiol Res. 2017;4:125-33.

15. Mooradian AD. Dyslipidemia in type 2 diabetes mellitus. Nat Clin Pract Endocrinol Metab. 2009;5:150-9. doi: 10.1038/ncpendmet 1066

16. Gaziano TA, Gaziano JM. Braunwald's Heart Disease: A textbook of Cardiovascular Medicine. Philadelphia: Saunders-Elsevier; 2012.

17. Intensive blood-glucose control with sulphonylureas or insulin compared with conventional treatment and risk of complications in patients with type 2 diabetes (UKPDS 33). UK Prospective Diabetes Study (UKPDS) Group. Lancet. 1998;352:837-53.

18. Ketema EB, Kibret KT. Correlation of fasting and postprandial plasma glucose with HbAlc in assessing glycemic control; systematic review and meta-analysis. Arch Pub Health. 2015;73:43. doi: 10.1186/s13690-015- 
0088-6

19. Syed IAA, Khan WA. Glycated haemoglobin-a marker and predictor of cardiovascular disease. J Pakistan Med Assoc. 2011;61:690.

20. Shahsavar F, Varzi AM, Ahmadi SA. A genomic study on distribution of human leukocyte antigen (HLA)-A and HLA-B alleles in Lak population of Iran. Genom Data. 2017;11:3-6. doi: 10.1016/j.gdata.2016.11.012

21. Varzi AM, Shahsavar F, Tarrahi MJ. Distribution of HLA-DRB1 and HLA-DQB1 alleles in Lak population of Iran. Hum Immunol. 2016;77:580-3. doi: 10.1016/j. humimm.2016.05.011

22. Laufs U, Filipiak KJ, Gouni-Berthold I, Catapano AL. Practical aspects in the management of statin-associated muscle symptoms (SAMS). Atheroscler Suppl. 2017;26:4555. doi: 10.1016/s1567-5688(17)30024-7

23. Karami A, Baradaran A. Comparative evaluation of three different methods for $\mathrm{HbA}(1 \mathrm{c})$ measurement with Highperformance liquid chromatography in diabetic patients.
Adv Biomed Res. 2014;3:94. doi: 10.4103/2277-9175.129364

24. Thevarajah $M$, Nadzimah $M$, Chew $Y$. Interference of hemoglobinAlc (HbA1c) detection using ion-exchange high performance liquid chromatography (HPLC) method by clinically silent hemoglobin variant in University Malaya Medical Centre (UMMC)-A case report. Clin Biochem. 2009;42:430-4. doi: 10.1016/j.clinbiochem.2008.10.015

25. WHO. Use of glycated haemoglobin (HbA1c) in diagnosis of diabetes mellitus: abbreviated report of a WHO consultation. Geneva: WHO; 2011.

26. Abdallah E, Ali A, Abdullah A. Impact of uncontrolled glycosylated hemoglobin on contrast-induced acute kidney injury in patients with type 2 diabetes mellitus undergoing percutaneous coronary intervention. J Prev Epidemiol. 2018;3:e03.

27. O'neill S, O’driscoll L. Metabolic syndrome: a closer look at the growing epidemic and its associated pathologies. Obes Rev. 2015;16:1-12. doi: 10.1111/obr.12229

Copyright $\odot 2018$ The Author(s); Published by Society of Diabetic Nephropathy Prevention. This is an open-access article distributed under the terms of the Creative Commons Attribution License (http://creativecommons.org/licenses/by/4.0), which permits unrestricted use, distribution, and reproduction in any medium, provided the original work is properly cited. 